\title{
Towards more sustainable synthesis of diketopyrrolopyrroles
}

By Flavia Pop,* a,b Joshua Humphreys, ${ }^{\mathrm{a}, \mathrm{b}}$ Jesper Schwarz, ${ }^{\mathrm{a}, \mathrm{b}}$ Liam Brown, ${ }^{\mathrm{a}, \mathrm{b}}$ Ashmiani van den Berg, ${ }^{a}$ David B. Amabilino* a,b

a. School of Chemistry, The University of Nottingham, NG7 2RD Nottingham, UK.

b. GSK Carbon Neutral Laboratories for Sustainable Chemistry, The University of Nottingham, Jubilee Campus, Triumph Road, Nottingham, NG7 2 TU, UK.

\section{ABSTTRACT}

The alkylation of 1,4-diketo-3,6-arylpyrrolo[3,4-c]pyrroles (ArDPP) is one of the most important steps in the synthesis of soluble materials based on these molecules and the polymers derived from them (that are employed widely in putative organic solar cells). Here we report an improvement in their method of synthesis replacing habitual solvent and base. Compared with more usual conditions, we employed acetonitrile as solvent to give higher or similar yields, with less toxic and hazardous waste, lower reaction time and temperature, and allows recycling of unreacted starting materials. Unlike dimethylformamide and $\mathrm{N}$-methylpyrrolidone, which are the most commonly employed solvents. Our reaction conditions have been tested on three different ArDPPs $(\mathrm{Ar}=$ thiophene, phenyl and 4-methoxyphenyl) with a variety of linear and branched alkyl reagents. The results show similar and improved results in comparison with the published reports while reducing the waste and hazard of the reaction, as well as simplifying the purification of the products in many cases. Overall this method has lower environmental impact, is more cost effective and requires neither the use of dry solvent nor inert atmosphere.

\section{Introduction}

Since its discovery in the late nineteen seventies ${ }^{1}$ and the publication of the first commercially available pigment, ${ }^{2}$ 1,4-diketopyrrolo[3,4-c] pyrroles (DPPs, Fig. 1) derivatives have shown a growing research interest. Over the past decade the number of scientific reports has grown by a factor of ten compared to the first twenty years, among which over $20 \%$ were reported last year, ${ }^{3}$ highlighting the broad interest in DPP based materials. The DPP core has a planar rigid structure that can induce strong intermolecular interactions such as hydrogen bonding and $\pi-\pi$ stacking making it extremely insoluble in most common solvents. ${ }^{4,5}$ While the DPPs with hydrogen atoms at the R position (Fig. 1) are quite insoluble in general (and are therefore used as pigments), alkylation of the nitrogen atom produces very soluble materials. Hence the growing interest in them in recent years as, for example, fluorescent probes, ${ }^{6}$ solution processed active layer constituents in organic photovoltaics and organic fieldeffect transistors, ${ }^{7-9}$ as well as triplet fusion up-conversion materials that have a number of potential uses. ${ }^{10}$

DPP chromophores consist of two condensed lactam units that are most habitually decorated by aromatic rings and at the lateral amide-nitrogen atoms by alkyl chains. ${ }^{11,12}$ Because of their excellent photophysical properties and stability, DPP based materials are being used nowadays as high-performance pigments ${ }^{13}$ and semiconductors in electronic devices. ${ }^{14}$ The $1,4-$ diketo3,6-dithienylpyrrolo[3,4-c] pyrrole (TDPP) derivatives are the most widely studied for a number of reasons, including synthetic availability $^{2}$ and flat conformation which results in good $\pi$-delocalization and intermolecular $\pi-\pi$ stacking. ${ }^{15}$ Similarly, the units attached to the lactam nitrogen atoms in the core DPP to increase solubility and processing ease are hydrocarbon chains, the most common being 2-ethylhexyl. Nevertheless any substituent at the nitrogen atom imparts solubility by preventing the formation of intermolecular hydrogen bonds, the nature of the alkyl groups allowing mainly its modulation. Thus, for most of the targeted applications that require certain solubility of the materials based on DPPs, the alkylation reaction becomes among the first and most important synthetic steps.

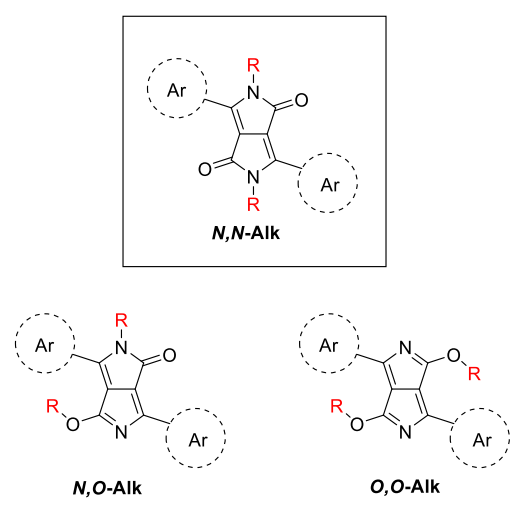

Fig. 1 Chemical structure of 1,4-diketo-pyrrolo[3,4-c $]$ pyrroles (DPPs, in the box) and the positions of substitution of side-products from the alkylation reaction of R=H. 
Similar to amides chemistry, the control of the alkylation position depends on the reaction conditions (basic or neutral), solvent and the temperature. ${ }^{16}$ In neutral conditions the $O$-alkylation is favoured at low temperature, being the kinetically stable product, while under thermodynamic control $\mathrm{N}$-alkylation was predominantly observed. At high temperatures, over increased reaction time and excess of alkylation reagents thermal rearrangement is also possible, which explains the presence of both $N$ and $O$-alkylation products. Under basic conditions DPPs are deprotonated to give anions in which the charges are distributed between the two heteroatoms making thus possible the alkylation at either or both $N$ - and $O$ - atoms. ${ }^{11,17}$ The usual alkylation method uses aprotic polar solvents such as dimethylformamide (DMF) and $N$-methylpyrrolidone (NMP) while the most employed bases to deprotonate the amide-NH are potassium carbonate, potassium hydroxide, ${ }^{18}$ potassium tert-butoxide ${ }^{19}$ and sodium hydride. ${ }^{20,21}$ While reactions performed in DMF have been shown to form mixtures of $N, N$-alkylated, $O, O$-alkylated and $\mathrm{N}, \mathrm{O}$-alkylated DPP derivatives ${ }^{22,23}$ (Figure 1), NMP has been reported to give in some cases the advantage of selective $\mathrm{N}, \mathrm{N}$ alkylation. ${ }^{24}$ In both cases the reaction conditions apparently require the use of dry solvents and stirring at high temperature $(\geq$ $120{ }^{\circ} \mathrm{C}$ ) for several hours under inert atmosphere. According to literature data, the yield of the dialkylation reaction is highly dependent on the conditions (solvent, base and temperature) ${ }^{22}$ as well as on the nature of the alkylating agent, linear or branched, and its leaving group, I or Br being the most common. The highest reported yields on TDPPs go up to $73 \%$ and $92 \%$ for branched and linear chains, respectively, and were obtained in DMF with potassium carbonate, while purification was done by recrystallization from DMF. ${ }^{25}$ In that report, the anion-activating catalyst 18 -crown-6 was used. Less data exists in the literature concerning the alkylation reaction of 1,4-diketo-3,6-diphenylpyrrolo[3,4-c]pyrroles (PhDPP), but in general the methods are similar to those of TDPP, using either DMF or NMP with potassium carbonate ${ }^{26-29}$ or potassium tert-butoxide. ${ }^{19}$ In some cases caesium carbonate $\left(\mathrm{Cs}_{2} \mathrm{CO}_{3}\right)$ was used as a base, in $\mathrm{DMF}$ at $120^{\circ} \mathrm{C}$, and the reported yields for the dialkylated TDPPs with branched units were between $16-25 \%^{30}$ and of about $38 \%^{31}$ for 2-branched-iodo and 2-,3-,4- or 5-branched-iodo alkylating reagent, respectively. Similar conditions, $\mathrm{Cs}_{2} \mathrm{CO}_{3}$ and $\mathrm{DMF}$, on 1,4-diketo-3,6-di-4-bromo-phenylpyrrolo[3,4-c $]$ pyrroles (BrPhDPP) gave yields between $28-60 \%$ with linear chains ${ }^{32,33}$ and about $22 \%$ for ethyl-hexyl unit. ${ }^{32}$

The need of reducing the environmental impact of chemical processes ${ }^{34,35}$ has driven us to look into the alkylation reaction of the DPP derivatives which is the first important step in the formation of soluble materials based on these molecules. In general, a large part of the materials used in synthetic processes are the solvents therefore their improvement represents an efficient way of developing greener and more sustainable synthetic routes. ${ }^{36,37}$ We report herein changes in the synthetic method which make it less energy demanding and less hazardous by using a greener replacement solvent. The solvent, acetonitrile, allowed lowering the temperature and occasionally the reaction time, and does not require drying (a process that would add to the energetic cost of the solvent) or working under inert atmosphere at this scale (although at a large scale an inert atmosphere would be needed as the solvent is above its flash point). Furthermore, it is considered perhaps the most acceptable polar aprotic solvents according to its over all ranking by Sanofi, being suggested as alternative for undesirable solvents of the aprotic polar family, or considered "green" by other study. Besides the much milder reaction conditions, the newly developed conditions offer a simplified method of purification and give similar and, in some cases, superior yields compared to previously published data in the above mentioned conditions. Overall the conditions described in this work are more cost effective, less hazardous and have lesser environmental impact.

\section{Results and discussion}

According to the CHEM21 solvent selection guide by Prat et al.38 solvents can be ranked into four categories such as recommended, problematic, hazardous and highly hazardous. Combining data in solvent guides from pharmaceutical companies ${ }^{39}$ and taking into account safety, health and environment criteria, in their classification DMF and NMP, which are the most common solvents used in the alkylation of the DPPs, are both ranked hazardous (having high scores on health and environment). Reproductive toxicity, dermal and inhalation toxicity, are only a few of the issues with those solvents.40 Acetonitrile $(\mathrm{MeCN})$, a solvent which is part of the same aprotic polar family, was first ranked recommended and changed to problematic after discussions. ${ }^{38}$ In the aprotic polar family $\mathrm{MeCN}$ is considered as the only alternative to amides and usable for medicinal chemistry ${ }^{41}$ despite not being considered entirely green in some solvent selection guides because of the bad scores on life cycle and waste recycling. ${ }^{36,37,39,42-44}$ However, the use of acetonitrile involves a much lower reaction temperature than either NMP or DMF in most of the reported procedures. We present here acetonitrile as a very good alternative to DMF and NMP for the alkylation reaction of three of the most commonly used DPP derivative families, TDPP, PhDPP and 1,4-diketo-3,6-di-4methoxy-phenylpyrrolo[3,4-c]pyrroles (PhOMeDPP) (Fig. 2). 


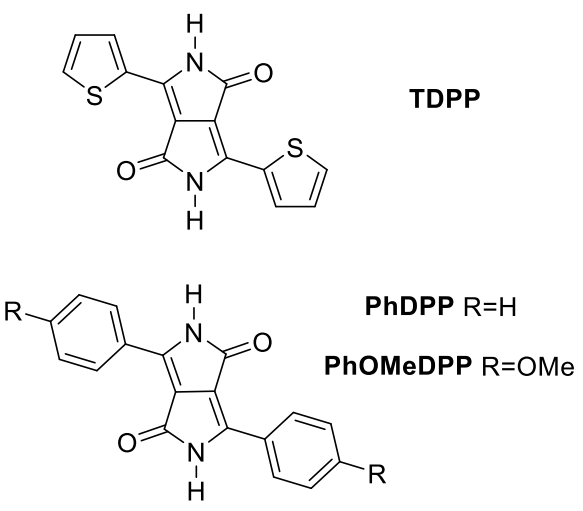

Fig. 2 Chemical structure of the DPPs investigated here.

When working in $\mathrm{MeCN}$ the best results have been obtained with caesium carbonate as base to deprotonate the amide-NH without the need of a crown ether (Scheme 1). The advantage of caesium carbonate in organic syntheses ${ }^{45}$ as well as for the $N$ alkylation of aromatic cyclic imides ${ }^{46}$ has been shown previously. In most of the cases, as well as in this particular reaction on DPP, the common solvents from the dipolar aprotic family are the DMF and the DMSO. For the alkylation of the DPP derivatives the main differences between the method in $\mathrm{MeCN}$ and the classical one in DMF are listed in Table 1.
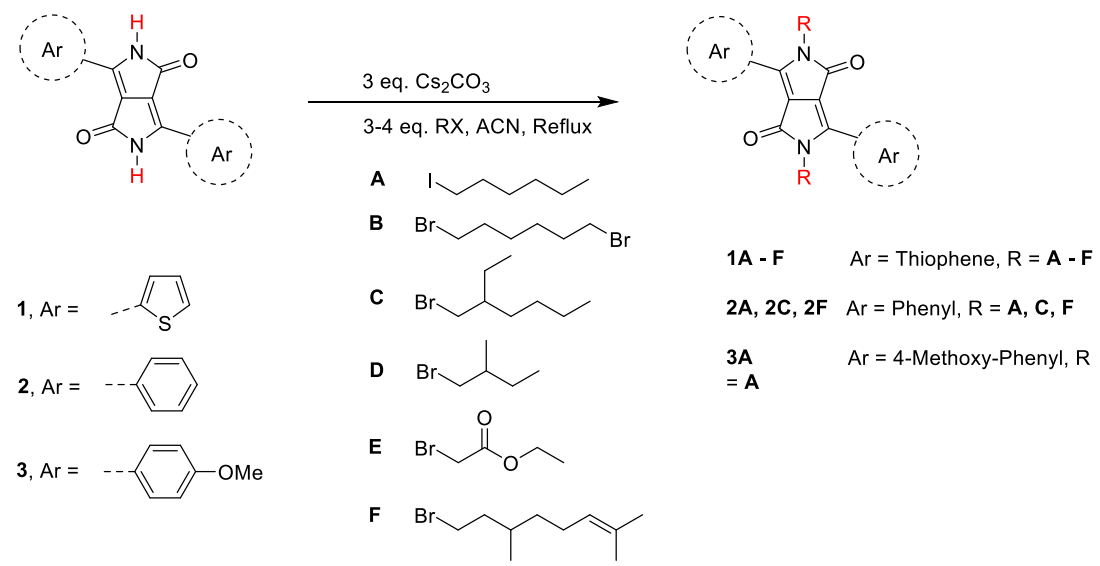

$=\mathbf{A}$

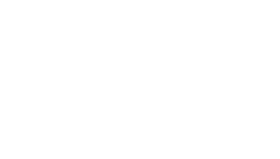

Scheme 1 Chemical structure of the DPPs investigated here.

Table 1. Advantages of the alkylation method from this work and the most common one in the literature.

\begin{tabular}{|c|c|}
\hline \multicolumn{1}{|c|}{$\mathrm{DMF} / \mathrm{K}_{2} \mathrm{CO}_{3}$ (literature) } & MeCN / $\mathrm{Cs}_{2} \mathrm{CO}_{3}$ (this work) \\
\hline$\times$ Dry solvent & $\checkmark$ No need for dry solvent \\
$\times$ Working under inert atmosphere & $\checkmark$ No need for working under inert atmosphere \\
$\times$ High reaction temperature $\left(\geq 120^{\circ} \mathrm{C}\right)$ & $\checkmark$ Lower reaction temperature (82 $\mathrm{C})$ \\
$\times$ No unreacted starting material recovered & $\checkmark$ Unreacted starting material recovered pure \\
Use of hazardous solvent for recrystallization (DMF) & Common purification methods: liquid/solid extraction and \\
Common purification method: chromatography & \\
\hline
\end{tabular}

The present alkylation method of DPPs has the advantage of using a greener solvent as well as straightforward purification and separation of the desired products from the reactions in isolated yields identical and sometimes superior to previously repor ted data. The use of MeCN as solvent allows facile separation of any unreacted starting material, excess of base and other inorganic salts, as well as straightforward separation of the different products $\mathrm{N}, \mathrm{N}$-alkylated from $\mathrm{O}, \mathrm{O}$-alkylated by difference in solubility for $\mathbf{1 A - 1 E}$ and by chromatography for $\mathbf{1 F}, \mathbf{2}$ and $\mathbf{3}$ (see Experimental section for details). An important advantage of the MeCN method is the recovery of unreacted DPPs which after drying could be straightaway reintroduced in repeat reactions. None of the tests we have made on the same reaction in DMF showed unreacted DPP and to our knowledge it has never been mentioned 
in the literature either. The materials in DMF show decomposition either as starting DPPs or as products possibly because of the long reaction time at high temperature and/or the formation of as yet unidentified side products.

Other conditions have been tested such as potassium carbonate in $\mathrm{MeCN}$, together with other solvents, such as acetone and tetrahydrofuran, but none gave encouraging results. Tables 2 and 3 gather data from the literature of the highest yields (excepting patents) reported on the alkylation with different alkylation agents, most of them being in DMF, together with our results on the alkylation in $\mathrm{MeCN}$ with both caesium and potassium carbonates. Caesium carbonate has been occasionally used with DMF but the reported yields did not exceed $38 \%$ on TDPP ${ }^{23,24}$ and only one report of $60 \%$ was found on BrPhDPP. 25,26 Our results show that three equivalents of base and alkyl agent were sufficient for attaining highest yields in most of the tested reactions whereas the literature very often reports the use of larger excess. When the conversion was low (see Table 4 for details), mainly with the less reactive branched alkyl units, the amount used was increased to four equivalents, the alkyl agent was added dropwise and the reaction time was increased (Table 4).

Table 2. Comparison of yields reported in literature and from this work on TDPPs.

\begin{tabular}{|c|c|c|c|}
\hline & $\mathrm{H}$ & $\frac{\text { Base }}{\mathrm{RX} \text {, Solvent, Heat }}$ & $T^{\mathrm{R}}{ }^{\mathrm{N}}=0$ \\
\hline DPP & Alkyl-X & $\begin{array}{l}\text { Yield (literature) } \\
\text { DMF, } \mathrm{K}_{2} \mathrm{CO}_{s} \text { (eq.) }\end{array}$ & $\begin{array}{c}\text { Yield (this work) } \\
\mathrm{MeCN}, \mathrm{Cs}_{2} \mathrm{CO}_{s} \text { (eq.) } 82^{\circ} \\
\mathrm{C}\end{array}$ \\
\hline $1 \mathrm{~A}$ & Hex-I & $12\left(3 \text { eq., } 90^{\circ} \mathrm{C}\right)^{\mathrm{a}}$ & $75(3 \text { eq. })^{c}$ and $10(4 \text { eq. })^{g}$ \\
\hline $1 \mathrm{~A}$ & Hex-Br & $81\left(3.3 \text { eq., } 120^{\circ} \mathrm{C}\right)^{\mathrm{b}}$ & \\
\hline 1B & Br-Hex-Br & $52\left(2.4 \text { eq. } \mathrm{KOH}, 65^{\circ} \mathrm{C}\right)^{18}$ & $86(1 \mathrm{eq} .)^{\mathrm{c}}$ \\
\hline $1 \mathrm{C}$ & EtHex-Br & $\begin{array}{c}76\left(4 \text { eq., } 145^{\circ} \mathrm{C}\right)^{45} \\
22\left(3.1 \text { eq. } \mathrm{Cs}_{2} \mathrm{CO}_{3}, 40^{\circ} \mathrm{C}\right) \mathrm{e}\end{array}$ & 56 (4 eq. $)^{\mathrm{d}}$ \\
\hline 1D & $(S)-\mathrm{MeBu}-\mathrm{Br}$ & $34\left(3.3 \text { eq., } 120^{\circ} \mathrm{C}\right)^{\mathrm{b}}$ & 33 (4 eq. $)^{d}$ \\
\hline $1 \mathrm{E}$ & EtOAc-Br & $68\left(\text { NMP, } 10 \text { eq., } 120^{\circ} \mathrm{C}\right)^{\mathrm{f}}$ & 81 (3 eq.) \\
\hline $1 \mathrm{~F}$ & $(S)$-3,7-diMeOctene-Br & 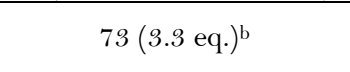 & $\begin{array}{c}28 \text { (3 eq., } 12 \mathrm{~h}) \\
33 \text { (3eq., } 7 \mathrm{~h})\end{array}$ \\
\hline
\end{tabular}

All experimental yields are calculated based on the reacted/converted starting material and isolated pure material; ${ }^{\text {a }}$ Reaction was done at $90^{\circ} \mathrm{C}$ for $24 \mathrm{~h}$, the authors do not clearly specify if hexyl-iodide or -bromide has been used ${ }^{29}$; b Catalytic amount of 18 -crown-6 was used and the product was isolated by recrystallization from DMF ${ }^{25}$; c Complete conversion; the rest of the material was $O, O$-alkylated and/or mono-alkylated products; ${ }^{\mathrm{d}}$ Addition of KI was required but complete conversion was not achieved for either increased reaction time and amount of reagents; ${ }^{\mathrm{e}} \mathrm{Cs}_{2} \mathrm{CO}_{3}$ was used instead of $\mathrm{K}_{2} \mathrm{CO}_{3}$ in $\mathrm{DMF}^{32}$; ${ }^{\mathrm{f}} \mathrm{NMP}$ was used as solvent. Final product was isolated by precipitation with water from $\mathrm{DMF}^{47}$; $\mathrm{g}$ Yield within this work in $\mathrm{MeCN}, \mathrm{K}_{2} \mathrm{CO}_{3}$ (eq.) $82^{\circ} \mathrm{C}$.

Table 3. Comparison of yields reported in literature and from this work on PhDPPs.

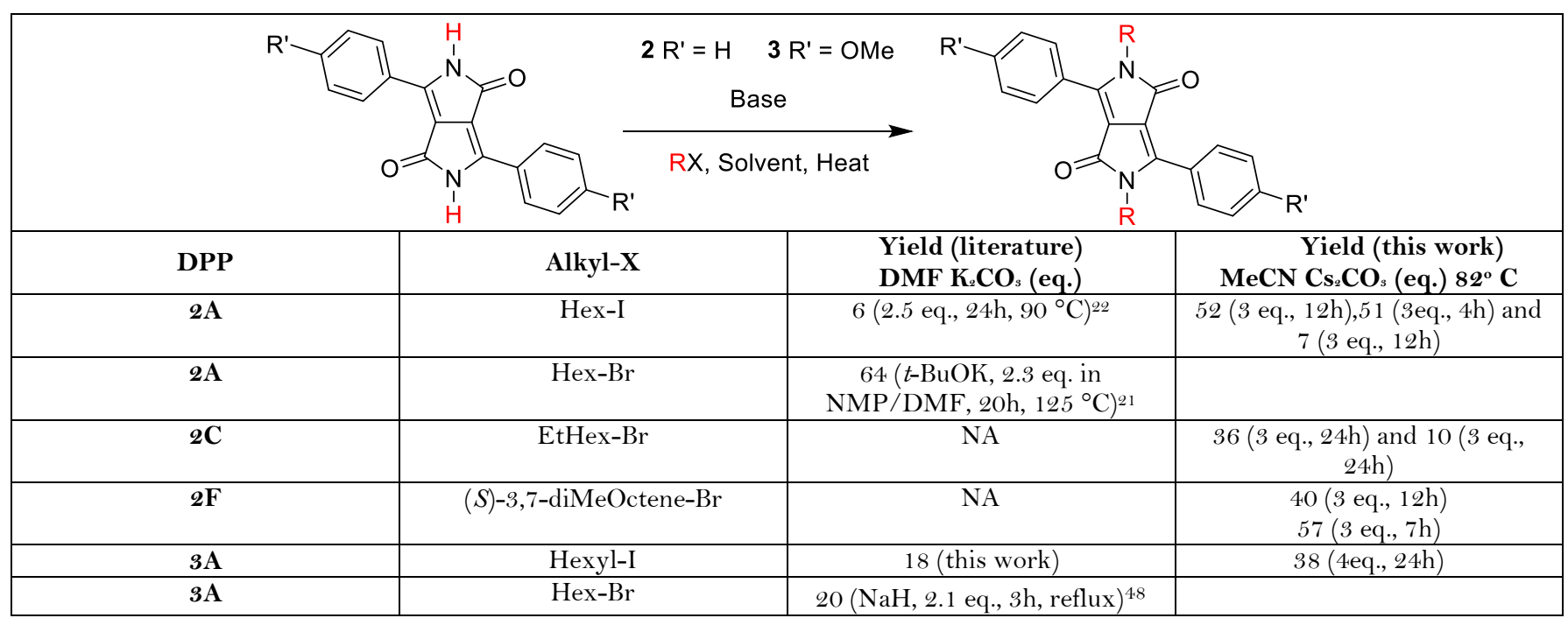

All experimental yields are calculated based on the reacted/converted starting material and isolated pure material; NA indicates results from these conditions not available. 
The published alkylation method has an apparent drawback: the lack of reproducibility in the yields of the reactions. In most cases the highest yields are reported in patents, although we and others ${ }^{48}$ have been unable to reproduce at least one of them, ${ }^{49}$ making the authenticity of their efficiency awaiting confirmation by scholarly authors. On the other hand, Geerts and coworkers $^{22}$ have screened reaction conditions on TDPP and 2-hexyl-decyl-bromide by varying the solvent, the base, the temperature and the addition of the alkyl halide. In all cases, they used polar solvents such as DMF, NMP and DMSO and varied the three parameters mentioned.

Table 4. Optimized conditions on the alkylation reaction in acetonitrile with caesium carbonate at reflux.

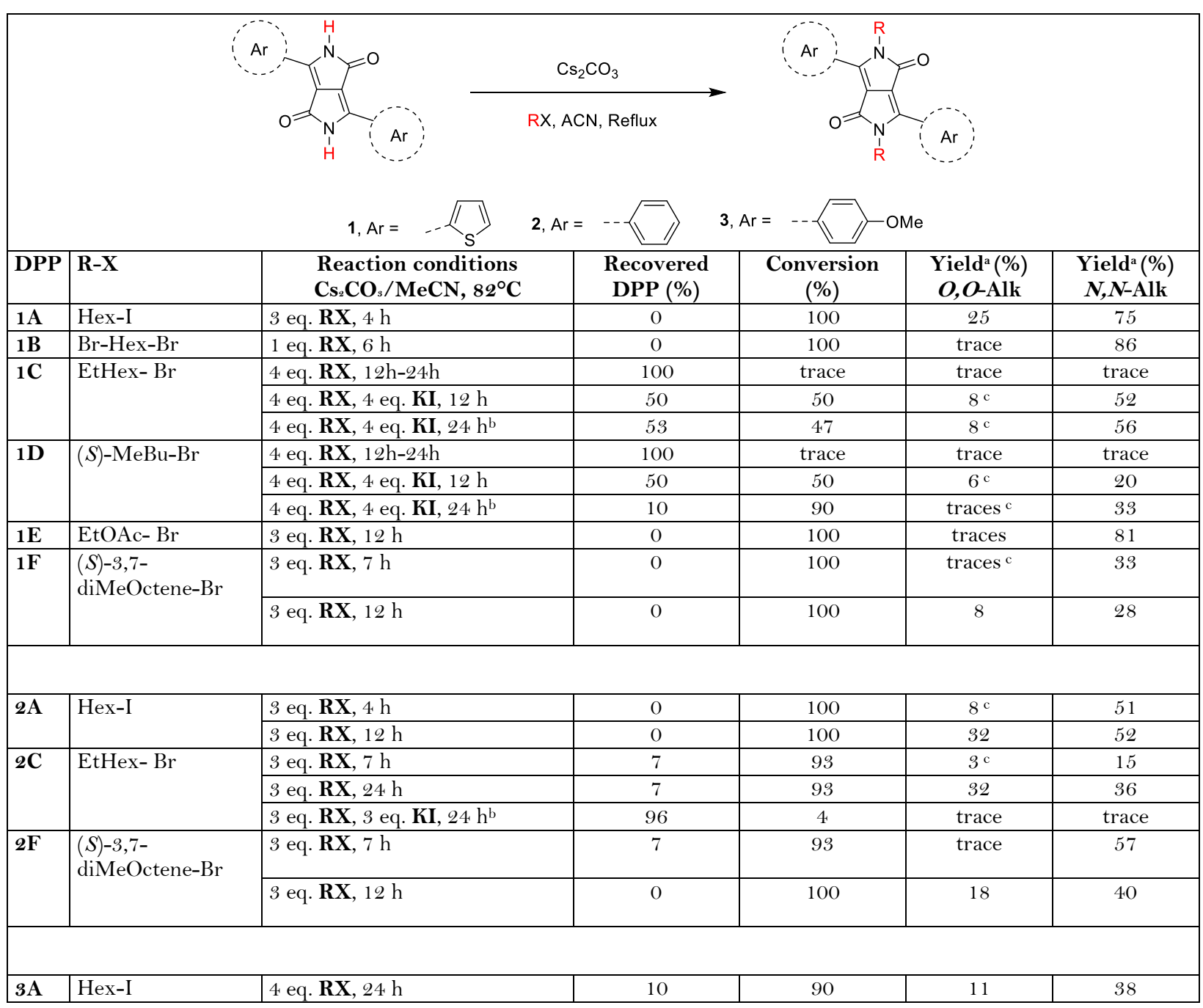

a Yields are calculated based on the reacted/converted starting material and isolated pure material.

${ }^{\mathrm{b}}$ Full conversion was never observed even for increased excess of used reagents (RX, base and KI).

${ }^{\mathrm{c}}$ For shorter reaction times mono-alkylated side products have been observed and isolated beside the $O, O$-di-alkylated products.

Changing the potassium carbonate for sodium hydride in DMF at $120{ }^{\circ} \mathrm{C}$ improved the yields from $11 \%$ to $19 \%$, whereas an increase in temperature (up to $140{ }^{\circ} \mathrm{C}$ ) together with changing the solvent gave essentially the same yield in NMP and a slightly higher value of $25 \%$ in DMSO. Adding dropwise the alkyl reagent during the reaction gave lower results every time. For the same alkyl reagent in $\mathrm{DMF} / \mathrm{K}_{2} \mathrm{CO}_{3}$ at high temperature, SciFinder database ${ }^{3}$ gives eight publications with yields superior to $25 \%$, the highest being of $56 \% .^{50}$ Similar high yields have been obtained with TDPP and other 2 -branched-bromides, such as $76 \%$ with 2 -butyl-octyl-bromide, ${ }^{51} 72 \%$ with 2 -octyl-dodecyl-bromide, ${ }^{52}$ and $76 \%$ with 2 -ethyl-hexyl-bromide. ${ }^{53}$ Overall from a total number of 346 hits on TDPP with any alkyl reagent only 52 have yields superior to $70 \%$ from which 23 are higher than $80 \%$ and only one reaches $92 \%$ when adding crown ether in the reaction. ${ }^{25}$ Among those, seventeen report the use of alkyliodides, both linear and branched, but only five claim yields superior to 50\%: methyl-I (86\%), ${ }^{22}$ 3,7,1 1-trimethyldodecyl-I $(67 \%), 54,55$ octyl-I and 3-ethylheptyl-I (58\% and 55\%), ${ }^{56}$ 2-decyltetradecyl-I (50\%). ${ }^{57}$ 
Our work on the synthesis of alkylated TDPP derivatives with various alkyl chains gave favourable results (similar and sometimes superior, Table 4) in comparison with the highest reported yields in the literature. However, we have observed lower reactivity and thus lower conversion with Br-alkyls (especially the 2-branched alkyl chains) in comparison with I-alkyls. When KI was added to the reaction mixture for in situ halogen exchange the yields were substantially improved and reached the highest values previously reported (Table 4, 1C and 1D).

For 1D the value we obtained is similar to the one reported in the literature using either $(S)$-2-methylbutane-bromide ${ }^{25}$ or iodide. $^{58}$ Surprisingly, adding KI to the reaction mixture in the case of the PhDPP seems to have the opposite effect, whereas alkyl bromides branched at the 3-position (F type) have proved to be reactive enough on both TDPP and PhDPP affording the desired product in good yields without performing the halogen exchange. This result suggests a lower reactivity of the alkyl chains branched at the 2-position in comparison with the 3-branched ones, possibly because of steric impediments from the branching point near the leaving group or a competing elimination reaction. This effect has not been observed for linear brominated chains. When using only one equivalent of the 1,6-dibromo-hexane in the conditions developed here, full conversion was achieved after only six hours of reaction and di-alkylated oligomeric chains were formed in $86 \%$ yield (Table 4 , 1B). The data reported in the literature on the reaction with hexyl-Br again vary broadly. From a total number of ten published papers the yields in $\mathrm{DMF}$ and $\mathrm{K}_{2} \mathrm{CO}_{3}$ are of $12 \%$ (at $90{ }^{\circ} \mathrm{C}$ for $24 \mathrm{~h}$ ), ${ }^{29} 64 \%$ (at $130{ }^{\circ} \mathrm{C}$, overnight), $5967 \%$ (at $100{ }^{\circ} \mathrm{C}$, for $36 \mathrm{~h}$, adding $18-$ crown-6) ${ }^{60}$ and going up to $75-78 \%$ (at $130{ }^{\circ} \mathrm{C}$ for $20-24 \mathrm{~h}$ ) 28,50 and $81 \%$ (at $120{ }^{\circ} \mathrm{C}$, overnight). ${ }^{25}$ With the present method both I-hexyl and 1,6-dibromo-hexane gave very good conversion and yields for shorter reaction time than the reported conditions in DMF. Occasionally we have observed lower overall yields for longer reaction time suggesting some decomposition during the reaction of starting materials and/or products $(\mathbf{1 D})$ and formation of higher amount of $O, O$-alkylated side products $(\mathbf{1 F}, \mathbf{2 A}, \mathbf{2 C}$ and $\mathbf{2} \mathbf{F})$.

To improve further the sustainability of our processes, we considered eradicating dichloromethane (DCM) in the purification steps. Compound $\mathbf{1 E}$ was chosen as a case study - as no column chromatography is required - and initially followed the standard work up for compounds $\mathbf{1 A - 1 E}$, with the crude product being washed with cold MeCN and water. A selection of solvents were then chosen as greener alternatives to DCM and $200 \mathbf{m g}$ of $\mathbf{1 E}$ was dissolved in $5 \mathrm{ml}$ of the solvent of choice and the product collected by suction filtration. Table 5 summarises the findings and it is observable that, despite its unfavourable environmental impact, DCM gives the highest yield resulting from this purification process. DCM and toluene afforded very clean NMR spectra of $\mathbf{1 E}$ from this process. On the contrary, the solubilised material using tetrahydrofuran (THF) and Me-THF for washing the initial solid showed multiple and abundant impurities, indicating a less selective dissolution for the desired $N, N$ alkyl product. In addition, repeated washings of the solid with larger volumes of solvents were required to dissolve the product. This result suggests that perhaps use of a small volume of halogenated solvent is preferable over larger volumes of somewhat less hazardous solvents for efficient purification of these derivatives.

Table 5. Comparison of yields for $1 \mathbf{E}$ when washed with various solvents to afford pure product

\begin{tabular}{|c|c|}
\hline Solvent & Yield $^{\mathrm{a}}(\%)$ \\
\hline Toluene & 18 \\
\hline Me-THF & $24^{\mathrm{b}}$ \\
\hline DCM & 81 \\
\hline THF & $59^{\mathrm{b}}$ \\
\hline MeOH & not soluble \\
\hline EtOAc & poor solubility \\
\hline
\end{tabular}

a Yields are calculated based on the reacted/converted starting material and isolated pure material.

b After repeated washings to obtain pure product

As a second case study, the extraction of $\mathbf{3 A}$ was similarly found to require larger volumes of alternative solvents compared to DCM, but in all cases for this compound, column chromatography was required to afford the pristine pure product. It was later found, upon testing solvent mixtures for flash chromatography (here DCM could not be avoided in the end because of poor solubility or separation), that after washing the crude product with water, dissolving the solid in heptane and adding a similar volume of methanol as anti-solvent, the desired $N, N$-alkyl product crystallised at the phase boundary between the two solvents. This solid could then be collected by filtration, affording the pure product at a slightly lower yield of $32 \%$ but eliminating the need for halogenated solvent usage in chromatography. This is not observed to be general behaviour and is in fact dependent on solubility traits of the molecule of interest.

Solubility was found to be one of the main challenges in the investigation of alternative eluent systems for flash chromatography, with precipitation of the material occurring in ethyl acetate (EtOAc):Hexane for TDPP and MeOH:Heptane for 3A. DCM is generally the preferred solvent for the work up of simple $N, N$-alkyl species, regardless of aryl unit, as 
derivatives display high solubility in the medium whereas for other solvents there is more of a functionalisation-dependent solubility. In cases where DCM is deemed the most suitable solvent for efficient purification, recovery of solvent can be utilised to minimise the volume of halogenated waste generated, and at least on the laboratory scale used here awaits identification of a more novel and effective replacement. Potential viable alternatives to DCM are seemingly acetone (or other ketones) and THF (or other cyclic ethers), although the latter is problematic ${ }^{38}$ and with the former there are again potential issues with precipitation upon addition of large quantities of non-polar solvent, as was the case for EtOAc.

\section{Conclusions}

The use of acetonitrile with caesium carbonate is beneficial both in terms of ease of work-up (and subsequent saving of materials used in this process), temperature of reaction, recycling of starting material, and hazard in the solvent than the most commonly used combinations of solvent and base for the alkylation of DPPs. In addition, drying of materials and the use of an inert atmosphere were found unnecessary. These advantages are attained with a similar PMI.

While caesium carbonate shows a clear advantage over the potassium salt in these reactions in acetonitrile, there is no clear advantage of one of the other in DMF according to the literature. In our hands, branched alkyl derivatives present a much greater challenge in their synthesis, longer reaction times leading to the usually undesired $O, O$-di-alkylated product. We are presently exploring alternatives to these groups ${ }^{61}$ in order to improve solubility of the DPPs in more environmentally responsible solvents while strengthening a more sustainable approach to these compounds, which are of increasing interest in molecular electronics and sustainable energy devices.

\section{Experimental}

\section{Materials and methods}

All commercially available reagents and solvents were used as received unless otherwise noted. Parent diketopyrrolopyrroles 1, $\mathbf{2}$, and $\mathbf{3}$ were synthesized following the general DPP synthesis protocol. ${ }^{2}$ Chromatography purifications were performed on Silica Gel (Sigma-Aldrich, pore size $60 \AA$, particle size 40-63 $\mu \mathrm{m}$ ), whereas thin-layer chromatography (TLC) was carried out on E. Merck silica gel plates using UV light to observe the products. All reactions were carried out under air unless otherwise specified. NMR spectra were acquired on a Bruker AV400 at room temperature in $\mathrm{CDCl}_{3}$ solutions. ${ }^{1} \mathrm{H}$ and ${ }^{13} \mathrm{C}$ NMR spectra were referenced to the residual protonated solvent $\left({ }^{1} \mathrm{H}\right)$ or the solvent itself $\left({ }^{13} \mathrm{C}\right)$. All chemical shifts are reported in $\delta$ units using the solvent residual signal as an internal standard and the coupling constant values $(J)$ are reported in Hertz $(\mathrm{Hz})$. The following abbreviations are used for signal multiplicities: s, singlet; d, doublet; t, triplet; dd, doublet of doublets; dt, doublet of triplets; ddd, doublet of doublet of doublets; tdd, triplet of doublet of doublets and m, multiplet. Mass spectroscopy with E SI-MS was done on Bruker micro-TOF II instrument.

\section{General synthetic procedure}

To a suspension of DPP (0.5 mmol) in acetonitrile $(20 \mathrm{~mL}) \mathrm{Cs}_{2} \mathrm{CO}_{3}(1.5 \mathrm{up}$ to $2 \mathrm{mmol})$ was added and the mixture was stirred at $82^{\circ} \mathrm{C}$ for one hour. The alkyl halide $\mathrm{R}-\mathrm{X}(1.5$ up to $2 \mathrm{mmol}$ ) was then added in one portion (in some cases when $\mathrm{X}=\mathrm{Br}, 1.5$ up to $2 \mathrm{mmol}$ of KI was added, see details in the discussions part). The reaction mixture was stirred at reflux under a fin condenser until no evolution of the reaction occurred.

Work-up of 1A-E. The reaction mixture was allowed to cool to room temperature (approx. $20{ }^{\circ} \mathrm{C}$ ) and the precipitate formed was collected by filtration. The filtrate $\mathrm{MeCN}$ solution was concentrated and the newly formed precipitated was filtered and washed with cold $\mathrm{MeCN}(30 \mathrm{~mL})$. The acetonitrile solution contains mostly $O, O$-Alk and $N, O$-Alk side-products whereas the $\mathrm{N}, \mathrm{N}$-Alk compounds are less soluble in cold acetonitrile. The precipitate was further washed with water (50 $\mathrm{mL})$ to remove any trace of inorganic salts. The desired $N, N$-Alk product was collected by extraction with DCM (50 mL). The insoluble coloured solid that was left on the filter paper, if any, was unreacted started material.

Work-up 1F, 2A, 2C, 2F. The reaction mixture was allowed to cool to room temperature (approx. $20{ }^{\circ} \mathrm{C}$ ) and the solvent was concentrated. The product was extracted with DCM $(30 \mathrm{~mL})$ and the remaining solid was collected by filtration and subsequent washing with DCM. The precipitate was further washed with water $(50 \mathrm{~mL})$ to remove any trace of inorganic salts. The insoluble coloured solid that was left on the filter paper, if any, was unreacted started material. The DCM solution filtrate was concentrated in vacuum and the crude purified by column chromatography on silica gel using mixture of DCM/hexane $9 / 1$ followed by DCM as eluents.

\section{Work-up 3A.}

Method A: The reaction mixture was allowed to cool to room temperature and the precipitate was filtered off using a No. 4 porosity glass sintered crucible. The solid was first washed with acetonitrile $(30 \mathrm{~mL})$ and contained a mixture of the $N, N$ and $O, O$ products. The solid was then washed with DCM $(30 \mathrm{~mL})$ to ensure only starting material remained. The filtrate was concentrated, washed with water $(30 \mathrm{~mL})$ and the organic phase extracted with DCM $(50 \mathrm{~mL})$. The product was then purified by column chromatography using an eluent system of 95:5 DCM: EtOAc. 
Method B: The reaction mixture was allowed to cool to room temperature and the precipitate was filtered off using a No. 4 porosity glass sintered crucible. The solid was first washed with water $(50 \mathrm{~mL})$ and then solubilised in DCM to ensure only starting material remained. The DCM filtrate was concentrated and then resolubilised in heptane. An equivalent volume of $\mathrm{MeOH}$ was then added as anti-solvent and the desired $N, N$-Alk product proceeded to crystallise at the phase boundary of the two solvents. The product was then collected by suction filtration.

Characterization of $1 \mathbf{F} .{ }^{1} \mathrm{H}$ NMR $(400 \mathrm{MHz}$, Chloroform- $d) \delta 8.93(\mathrm{dd}, J=3.9,1.2 \mathrm{~Hz}, 2 \mathrm{H}), 7.66(\mathrm{dd}, J=5.0,1.2 \mathrm{~Hz}, 2 \mathrm{H}), 7.31$ $(\mathrm{dd}, J=5.0,3.9 \mathrm{~Hz}, 2 \mathrm{H}), 5.11(\mathrm{ddd}, J=8.5,5.0,1.5 \mathrm{~Hz}, 2 \mathrm{H}), 4.22-4.04(\mathrm{~m}, 4 \mathrm{H}), 2.00(\mathrm{~m}, 4 \mathrm{H}), 1.84-1.74(\mathrm{~m}, 2 \mathrm{H}), 1.7 \mathrm{O}(\mathrm{s}, 6 \mathrm{H})$, $1.64-1.59(\mathrm{~m}, 2 \mathrm{H}), 1.57(\mathrm{~s}, 6 \mathrm{H}), 1.49-1.37(\mathrm{~m}, 2 \mathrm{H}), 1.26(\mathrm{tdd}, J=13.5,8.3,4.3 \mathrm{~Hz}, 4 \mathrm{H}), 1.04(\mathrm{~d}, J=6.3 \mathrm{~Hz}, 6 \mathrm{H}) .{ }^{13} \mathrm{C} \mathrm{NMR}$ $\left(101 \mathrm{MHz}, \mathrm{CDCl}_{3}\right) \delta 161.33,140.03,135.20,131.37,130.64,129.71,128.61,124.55,107.78,40.79,36.95,36.69,30.88,25.73$, 25.45, 19.40, 17.69. ESI-MS $m / z$ calculated for $\mathrm{C}_{34} \mathrm{H}_{44} \mathrm{~N}_{2} \mathrm{O}_{2} \mathrm{~S}_{2}\left[M^{+}\right]: 576.28$, found: $[(M+\mathrm{H})]^{+} 577.29(86),[(M+\mathrm{Na})]^{+} 599.27$ (68), $[(M+\mathrm{K})]^{+} 615.24(100)$.

Characterization of $2 \mathbf{C} .{ }^{1} \mathrm{H}$ NMR $(400 \mathrm{MHz}$, Chloroform- $d) \delta 7.83-7.73(\mathrm{~m}, 4 \mathrm{H}), 7.58-7.49(\mathrm{~m}, 6 \mathrm{H}), 3.83-3.68(\mathrm{~m}, 4 \mathrm{H}), 1.49$ $(\mathrm{dt}, J=14.5,7.3 \mathrm{~Hz}, 2 \mathrm{H}), 1.38-0.98(\mathrm{~m}, 16 \mathrm{H}), 0.80(\mathrm{t}, J=6.8 \mathrm{~Hz}, 6 \mathrm{H}), 0.71(\mathrm{t}, J=7.4 \mathrm{~Hz}, 6 \mathrm{H}) .{ }^{13} \mathrm{C} \mathrm{NMR}\left(101 \mathrm{MHz}, \mathrm{CDCl}_{s}\right) \delta$ $162.77,148.71,130.87,128.81,128.62$, 109.77, 44.91, 38.52, 30.31, 28.26, 23.72, 22.83, 13.94, 10.37. ESI-MS $\mathrm{m} / z$ calculated for $\mathrm{C}_{38} \mathrm{H}_{48} \mathrm{~N}_{2} \mathrm{O}_{2}\left[M^{+}\right]: 564.37$, found: $[(M+\mathrm{H})]+565.37(100),[(M+\mathrm{Na})]+587.35(78),[(M+\mathrm{K})]+603.33(97)$.

Characterization of $2 \mathbf{F}$. ${ }^{1} \mathrm{H}$ NMR $(400 \mathrm{MHz}$, Chloroform- $d) \delta 7.83(\mathrm{dd}, J=7.7,2.0 \mathrm{~Hz}, 4 \mathrm{H}), 7.59-7.52(\mathrm{~m}, 6 \mathrm{H}), 5.03(\mathrm{t}, J=8.4$ $\mathrm{Hz}, 2 \mathrm{H}), 3.87-3.72(\mathrm{~m}, 4 \mathrm{H}), 1.90(\mathrm{dt}, J=16.9,7.5 \mathrm{~Hz}, 4 \mathrm{H}), 1.67(\mathrm{~s}, 6 \mathrm{H}), 1.57(\mathrm{~m}, 6 \mathrm{H}), 1.5 \mathrm{O}-1.4 \mathrm{O}(\mathrm{m}, 4 \mathrm{H}), 1.33-1.21(\mathrm{~m}, 4 \mathrm{H})$, $1.19-1.07(\mathrm{~m}, 2 \mathrm{H}), 0.85(\mathrm{~d}, J=6.3 \mathrm{~Hz}, 6 \mathrm{H}) .{ }^{13} \mathrm{C} \mathrm{NMR}\left(101 \mathrm{MHz}, \mathrm{CDCl}_{3}\right) \delta 162.64,148.48,131.33,131.12,128.88,128.67$, $128.31,128.25,124.47,109.76,40.26,36.73,36.30,30.47,25.70,25.31,19.27,17.66$. ESI-MS $m / z$ calculated for $\mathrm{C}_{34} \mathrm{H}_{44} \mathrm{~N}_{2} \mathrm{O}_{2}$ $\left[M^{+}\right]$: 512.34, found: $[(M+\mathrm{H})]^{+} 513.34(100),[(M+\mathrm{Na})]^{+} 535.33(78),[(M+\mathrm{K})]^{+} 551.30(86)$.

\section{Conflicts of interest}

"There are no conflicts to declare".

\section{Acknowledgements}

We thank the EPSRC (project EP/Mo05178/1) and the School of Chemistry at the University of Nottingham for funding.

\section{References}

1 D. G. Farnum, G. Mehta, G. G. I. Moore and F. P. M. Siegal, Tetrahedron Lett., 1974, 29, 2549.

2 L. Cassar, A. Iqbal, A. C. Rochat, J. Pfenninger and O. Wallquist, J. Coat. Technol., 1988, 60, 37.

3 Number of publications based on SciFinder database (https://scifinder.cas.org).

4 Z. Hao and A. Iqbal, Chem. Soc. Rev., 1997, 26, 203.

5 C. Fu, P.J. Beldon and D.F. Perepichka, Chem. Mater., 2017, 29, 2979.

6 M. Kaur and D. H. Choi, Chem. Soc. Rev., 2015, 44, 58.

7 Y. N. Li, P. Sonar, L. Murphy and W. Hong, Energy Environ. Sci., 2013, 6, 1684.

D. Chandran and K. S. Lee, Macromol. Res., 2013, 21, 272.

W. Li, K.H. Hendriks, M.M. Wienk and R.A.J. Janssen, Acc. Chem. Res., 2016, 49, 78.

10 A.B. Pun, L.M. Campos, and D.N. Congreve, J. Am. Chem. Soc., Article ASAP, DOI: 10.1021/jacs.8b11796

11 M. Grzybowski and D. T. Gryko, Adv. Optical Mater., 2015, 3, 280.

12 C. Kim, J. Liu, J. Lin, A. B. Tamayo, B. Walker, G. Wu and T.-Q. Nguyen, Chem. Mater., 2012, 24, 1699.

13 Y. Qu, J. Hua and H. Tian, Org. Lett., 2010, 12, 3320.

14 Q. Liu, A. Surendran, K. Feron, S. Manzhos, X. Jiao, C. R. McNeill, S.E. Bottle, J. Bell, W.L. Leong and P. Sonar, New J. Chem., 2018, 42, 4017 .

15 F. Pop, W. Lewis and D. B. Amabilino, CrystEngComm, 2016, 18, 8933.

16 J. Zabicky, The Chemistry of Amides; Interscience Publishers: London, 1970, 159.

17 S. A. Shevelev, Russ. Chem. Rev., 1970, 39, 844.

18 Y. Cai, Q. Tang, X. Wu, W. Si, Q. Zhang, W. Huang and X. Dong, ACS Appl. Mater. Interfaces, $2016,8,10737$.

19 S. Celik, Y. Ergun and S. Alp, J. Fluoresc., 2009, 19, 829.

20 C. H. Woo, P. M. Beaujuge, T. W. Holcombe, O. P. Lee and J. M. J. Frechet, J. Am. Chem. Soc., $2010,132,15547$.

21 A. T. Yiu, P. M. Beaujuge, O. P. Lee, C. H. Woo, M. F. Toney and J. M. J. Frechet, J. Am. Chem. Soc., 2012, 134, 2180.

22 S. Stas, S. Sergeyev and Y. Geerts, Tetrahedron, 2010, 66, 1837.

23 Š. Frebort, Z.Eliáš, A. Lycka, S. Lunak Jr., J. Vynuchal, L. Kubac, R. Hrdina and L. Burgert, Tetrahedron Lett., $2011,52,5769$.

24 S. Stas, J.-Y. Balandier, V. Lemaur, O. Fenwick, G. Tregnago, F. Quist, F. Cacialli, J. Cornil and Y. H. Geerts, Dyes and Pigments, $2013, \mathbf{9 7}, 198$.

25 M. Kirkus, L. Wang, S. Mothy, D. Beljonne, J. Cornil, R. A. J. Janssen and S. C. J. Meskers, J. Phys. Chem. A, $2012,116,7927$.

26 M. Fukuda, K. Kodama, H. Yamamoto and K. Mito, Dyes and Pigments, 2004, 63, 115. 
27 G. Colonna, T. Pilati, F. Rusconi and G. Zecchi, Dyes and Pigments, 2007, 75, 125.

28 J. Dhar, N. Venkatramaiah, A. Anitha and S. Patil, J. Mater. Chem. C, $2014,2,3457$.

29 P. Data, A. Kurowska, S. Pluczyk, P. Zassowski, P. Pander, R. Jedrysiak, M. Czwartosz, L. Otulakowski, J. Suwinski, M. Lapkowski and A.P. Monkman, J. Phys. Chem. C, 2016, 120, 2070.

30 O. P. Lee, A. T. Yiu, P. M. Beaujuge, C. H. Woo, T. W. Holcombe, J. E. Millstone, J. D. Douglas, M. S. Chen and J. M. J. Fréchet, Adv. Mater., $2011, \mathbf{2 3}, 5359$.

31 C. Wang, Y. Qin, Y. Sun, Y.-S. Guan, W. Xu and D. Zhu, ACS Appl. Mater. Interfaces, $2015,7,15978$.

32 C. Kim, J. Liu, J. Lin, A. B. Tamayo, B. Walker, G. Wu and T.-Q. Nguyen, Chem. Mater., $2012,24,1699$.

33 K. Chung, M. S. Kwon, B. M. Leung, A. G. Wong-Foy, M. Su Kim, J. Kim, S. Takayama, J. Gierschner, A. J. Matzger and J. Kim, ACS Cent. Sci., 2015, 1, 94.

34 P. G. Jessop, Green Chem., $2011, \mathbf{1 3}, 1391$.

35 S. M. Lee, H. R. Lee, A-R. Han, J. Lee, J. H. Oh and C. Yang, ACS Appl. Mater. Interfaces, $2017,9,15652$.

36 R. K. Henderson, C. Jimenez-Gonzalez, D. J. C. Constable, S. R. Alston, G. G. A. Inglis, G. Fisher, J. Sherwood, S. P. Binks and A. D. Curzons, Green Chem., $2011, \mathbf{1 3}, 854$.

37 C. P. Ashcroft, P. J. Dunn, J. D. Hayler and A. S. Wells, Org. Process Res. Dev., $2015,19,740$.

38 D. Prat, A. Wells, J. Hayler, H. Sneddon, C. R. McElroy, S. Abou-Shehadd and P. J. Dunn, Green Chem., $2016,18,288$.

39 F. P. Byrne, S. Jin, G. Paggiola, T. H. M. Petchey, J. H. Clark, T. J. Farmer, A. J. Hunt, C. R. McElroy and J. Sherwood, Sustain. Chem. Process., $2016,4,7$.

40 L. Bergkamp and N. Herbatschek, RECIEL, 2014, 23, 221.

41 K. Alfonsi, J. Colberg, P. J. Dunn, T. Fevig, S. Jennings, T. A. Johnson, H. P. Kleine, C. Knight, M. A. Nagy, D. A. Perry and M. Stefaniak, Green Chem., 2008, 10, 31.

42 C. Capello, U. Fischer and K. Hungerbuhler, Green Chem., 2007, 9, 927.

43 V. Isoni, L.L. Wong, H.H. Khoo, I. Halim and P. Sharratt, Green Chem., 2016, 18, 6564.

44 J. H. Clark and S. J. Tavener, Org. Process Res. Dev., 2007,1 1, 149.

45 R. Rabie, M.M. Hammouda and K.M. Elattar, Res. Chem. Intermediates, 2017, 43, 1979.

46 M. Isasmendi Escudero, L. D. Kremenchuzky, I. A. Perillo, H. Cerecetto and M. M. Blanco, Synthesis, 2011 , 4, 571.

47 S. Lunák Jr., Z. Eliás, T. Mikyseka, J. Vynuchal and J. Ludvík, Electrochimica Acta, $2013,106,351$.

48 W.-K. Chan, Y. Chen, Z. Peng and L. Yu, J. Am. Chem. Soc., 1993, 115, 11735.

49 C. Keun, B, Jacsoon, L. Jacchol, L. Jiyoung, L. Hangken, J. Jinseck and L. Bogyu, US Patent No. 9,777,108, 2017.

50 J. Qi, J. Han, X. Zhou, D. Yang, J. Zhang, W. Qiao, D. Ma and Z. Y. Wang, Macromolecules, $2015,48,3941$.

51 L. Dou, J. Gao, E. Richard, J. You, C.-C. Chen, K. C. Cha, Y. He, G. Li and Y. Yang, J. Am. Chem. Soc., $2012,134,10071$.

52 M. A. Naik, N. Vnekatramaiah, C. Kanimozhi and S. Patil, J. Phys. Chem. C, $2012,116,26128$.

53 L. Huo, J. Hou, H.-Y. Chen, S. Zhang, Y. Jiang, T. L. Chen and Y. Yang, Macromolecules, $2009,42,6564$.

54 Z. Wu, B. Fan, A. Li, F. Xue and J. Ouyang, Org. Electron., 2011 , 12, 993.

55 Z. Wu, A. Li, B. Fan, F. Xue, C. Adachi and J. Ouyang, Sol. Energ. Mat. Sol. Cells, $2011,95,2516$.

56 J. Lucarelli, M. Lessi, C. Manzini, P. Minei, F. Bellina ans A. Pucci, Dyes and Pigments, $2016,135,154$.

57 S. Singh, S. Chithiravel and K. Krishnamoorthy, J. Phys. Chem. C, 2016, 120, 26199.

58 S. Rieth, Z. Li, C. E. Hinkle, C. X. Guzman, J. J. Lee, S. I. Nehme and A. B. Braunschweig, J. Phys. Chem. C, $2013,117,11347$.

59 A. B. Tamayo, M. Tantiwiwat, B. Walker and T.-Q. Nguyen, J. Phys. Chem. C, $2008,112,15543$.

60 S. P. Mishra, A. K. Palai and M. Patri, Synth. Met., $2010,160,2422$.

61 P.A. Hume, J.P. Monks, F. Pop, E. S. Davies, R.C.I. MacKenzie and D.B. Amabilino, Chem. Eur. J., $2018,24,14461$. 